\title{
Ler Pessoa. Dois estudos semânticos em torno de sua obra poética
}

\author{
Reading Pessoa. Two semantic studies about his poetic work
}

\author{
Lauro Gomes \\ Escola de Humanidades - PPGL - PUCRS/CAPES ${ }^{1}$ - Porto Alegre - Rio Grande do Sul - Brasil
}

\section{Giorgio Christopulos}

École des Hautes Études en Sciences Sociales- (CRAL/CNRS) - Paris - France

\begin{abstract}
Resumo: Este artigo tem por objetivo geral mostrar em que medida a interpretação é um fenômeno que - como a argumentação - está inscrito na própria natureza da língua. Com base nos estudos e pesquisas em Semântica Argumentativa, partimos da hipótese de que a significação das palavras é um fator determinante não apenas para a construção do sentido dos enunciados, mas também para o estabelecimento de um possível "percurso de leitura", por meio do qual se depreende o sentido global do discurso. A fim de elucidarmos - de um ponto de vista semântico - esse recurso essencialmente cognitivo que torna possível a interação entre os homens, analisamos dois discursos literários, a saber: um fragmento do Livro do desassossego, de Bernardo Soares, e o segundo poema de O Guardador de Rebanhos, de Alberto Caeiro, ambos de autoria desses dois referidos heterônimos de Fernando Pessoa. As análises desse corpus literário mostram que a interpretação textual está subordinada à significação das palavras, às relações entre as palavras, entre os enunciados, entre as partes do discurso, bem como às instruções que o enunciado dá de sua própria enunciação.
\end{abstract}

Palavras-chave: Interpretação. Semântica Argumentativa. Leitura. Escrita.

Abstract: This paper aims to demonstrate that interpretation is a phenomenon that - like argumentation - is inscribed in the nature of language. Based on studies and researches in Argumentative Semantics, we start from the hypothesis that the meaning of words is a determining factor not only for the construction of the meaning of utterances, but also for the establishment of a possible "reading path", from where extracts the global meaning of the discourse. In order to elucidate - from a semantic point of view - this essentially cognitive resource that makes possible the interaction between men, we analyze two literary discourses: a fragment of Bernardo Soares' The book of disquiet ( $O$ livro do desassossego), and the second poem by Alberto Caeiro's The Keeper of Sheep $(O$ Guardador de Rebanhos), both authored by these two Fernando Pessoa's heteronymous. The analysis of this literary corpus shows that the textual interpretation is subordinated to the meaning of words, to the relations between words, between utterances, between parts of discourse, as well as to the instructions that the utterance itself gives of its enunciation.

Keywords: Interpretation. Argumentative Semantics. Reading. Writing.

\footnotetext{
${ }^{1}$ Este artigo - por ter sido desenvolvido durante o estágio de Doutorado Sanduíche de Lauro Gomes na École des Hautes Études en Sciences Sociales, de Paris - teve o apoio da Coordenação de Aperfeiçoamento de Pessoal de Nível Superior (CAPES), por meio do Programa de Doutorado Sanduíche no Exterior (PDSE).
} 


\section{Introdução}

(L.G.)

Entre os temas que envolvem o funcionamento da linguagem humana, a interpretação ainda ganha a atenção de investigações linguísticas e literárias. Há quem diferencie interpretação de compreensão discursivaltextual e há quem absolutamente não faça nenhuma diferença entre esses dois termos teóricos. Para aqueles autores que aderem à referida distinção, interpretar geralmente diz respeito às operações cognitivas efetuadas pelo sujeito leitor durante o processo de leitura. Nesse caso, a interpretação, em si, pouco tem a ver com a materialidade discursiva, e a atividade de compreensão é entendida como um fenômeno que decorre, sobretudo, das relações (entre palavras, enunciados e parágrafos) estabelecidas no interior de um discurso/texto.

A posição que adotamos neste artigo está de acordo com a daqueles pesquisadores que tomam interpretação e compreensão como sinônimos perfeitos. No entanto, se se quiser guardar a referida diferença, deve-se entender compreensão em todos os nossos empregos do termo interpretação. Essa decisão vai ao encontro das postulações de Ducrot (1991), para quem a interpretação é um instrumento por meio do qual o semanticista acesso o seu objeto. Desse modo, é pela interpretação que o linguista semanticista acessa a significação da frase - o que, segundo o referido autor (1991, p. 307), constitui o seu objeto - e, por conseguinte, o sentido do enunciado, elemento notadamente recuperável a partir das indicações sobre a sua enunciação.

Ao longo deste artigo, buscamos mostrar em que medida a interpretação é um fenômeno que, a exemplo da argumentação, está inscrito na própria natureza da língua. Para tanto - com base em princípios e conceitos da Teoria dos Blocos Semânticos (TBS) - examinamos a significação e o sentido, respectivamente de palavras e de enunciados do segundo poema de $O$ Guardador de Rebanhos, de Alberto Caeiro, e de um excerto do Livro do desassossego, de Bernardo Soares, ambos heterônimos de Fernando Pessoa. Em vista disso, a justificativa principal desta pesquisa é pensar sobre o que chamamos "interpretação textual" de um ponto de vista estritamente linguístico.

\section{Ferramentas da Teoria dos Blocos Semânti- cos para a análise textual (L.G.)}

Criada por Marion Carel, em 1992, a Teoria dos Blocos Semânticos (TBS) radicaliza e aprofunda a teoria da Argumentação na Língua (Anscombre; Ducrot, 1983), sobretudo na medida em que descarta as hipóteses da Teoria dos Topoi (1988), segundo as quais certos elementos extralinguísticos são necessários, não apenas quando se busca explicar o sentido de enunciados de um discurso, mas também quando se quer descrever a significação das palavras da língua. Portanto, como a TBS destina-se a explicar a língua apenas a partir das relações argumentativas estabelecidas no discurso, pode-se dizer que ela constrói uma linguística que se concentra apenas nas palavras e suas relações.

O sentido de nossos enunciados não contém, segundo essa perspectiva, uma linha que divide a representação do mundo e a enunciação do locutor, pois o que nossos enunciados exprimem, de fato, são pontos de vista argumentativos, em que é impossível separar a representação do mundo, de um lado, e a enunciação do locutor, de outro. Desse modo, a TBS supõe que o conteúdo de nossos enunciados é parafraseável por encadeamentos argumentativos, também definidos como átomos semânticos, que relacionam duas proposições por um conector do tipo de portanto (normativo) ou por um conector do tipo de no entanto (transgressivo). Essa teoria visa a prever, enfim, essas paráfrases a partir da significação das palavras e de seu entrelaçamento.

São, por um lado, exemplos de encadeamentos argumentativos normativos as seguintes sequências (1), (2) e (3):

(1) O fogo se espalhava na parede, portanto Pedro chamou os bombeiros.

(2) A estrada estava molhada. Por isso, Pedro reduziu a velocidade. 
(3) Pedro tomou precaução, porque havia perigo.

Por outro lado, são exemplos de encadeamentos argumentativos transgressivos as seguintes sequências (4), (5) e (6):

(4) A noção era muito abstrata, no entanto Pedro a compreendeu rapidamente.

(5) A pergunta era difícil. Apesar disso, Pedro a respondeu rapidamente.

(6) Embora o texto fosse difícil, Pedro compreendeu-o rapidamente.

A TBS sustenta que esses encadeamentos argumentativos (paráfrases do sentido de enunciados) concretizam esquemas abstratos denominados aspectos argumentativos (inscritos na significação de palavras), construídos sob a fórmula $X$ CONECTOR Y. Assim, nesse caso, pode-se dizer que (1), (2) e (3) realizam um mesmo aspecto normativo do tipo de PERIGO DC PRECAUÇÃO, inscrito na significação de "prudente". Já os encadeamentos (4), (5) e (6) concretizam o mesmo aspecto argumentativo transgressivo DIFÍCIL PT COMPREENDE, inscrito na significação de inteligente.

Os encadeamentos desses dois grupos compartilham mais uma propriedade em comum: a de serem explicitamente evocados, já que, segundo explica Carel (2018), esses encadeamentos são evocados graças à significação das palavras do enunciado. De outra parte, há encadeamentos que são implicitamente evocados, uma vez que resultam de uma interpretação, isto é, vão além da significação das palavras empregadas no enunciado. Por essa razão, esses encadeamentos realizam-se a partir da rede argumentativa que a própria língua estabelece no interior do léxico ${ }^{2}$.

Propriedade semelhante a essa da evocação explícita ou implícita dos encadeamentos pode ser observada no nível dos aspectos. Trata-se, nesse caso, da decalagem, um tipo de comparação que -

\footnotetext{
${ }^{2}$ Exemplos dessas noções e propriedades dos encadeamentos também se encontram em Carel (2018, p. 111-113). Neste nosso artigo, elas são aplicadas sobretudo na análise do poema de Alberto Caeiro, conforme se pode verificar na seção 2.1.
}

segundo define e exemplifica Carel (2017) - pode ser banal, inesperada ou até mesmo absurda. Diz-se, então, que o sentido de um enunciado é "decalado" quando o encadeamento não é prefigurado pelo aspecto que concretiza; e isso é o que se vai verificar ao longo de toda a análise do poema de Caeiro. Em realidade, esse fenômeno da decalagem reflete uma das riquezas da língua, pois, como bem explica Carel (2017, p. 14), "o entrelaçamento das palavras permite instaurar, entre termos, relações que não estavam previamente inscritas na sua significação e, por isso, permite construir textos que não são o simples reflexo do sistema linguístico".

Em última instância, tanto os encadeamentos implicitamente evocados, quanto a decalagem revelam um ponto de vista que é fruto de uma apropriação da língua carregada pela singularidade do locutor. Fica muito claro, em decorrência, que enunciação e argumentação nunca se separam fenomenologicamente. Com as devidas ressalvas epistemológicas, poder-se-ia até mesmo dizer que esses dois fenômenos postulados no interior da TBS explicitam a tese saussuriana da indissociabilidade língua-fala, apresentada no Curso de linguística geral, e retomada nos Escritos de linguística geral, notadamente na Nota sobre o discurso (ELG, 2002, p. 277), por exemplo, em cujo primeiro enunciado Saussure afirma que "a língua só é criada em vista do discurso [...]".

Metodologicamente, enunciação e argumentação sempre foram estudadas por meio de ferramentas distintas no interior da Semântica Argumentativa, ou, em todo caso, não foram examinadas conjuntamente na e pela teoria de Ducrot e Anscombre. No entanto, as argumentações enunciativas - conforme postuladas por Carel (2018) - têm o objetivo de efetivamente inscrever a enunciação no interior do sentido do enunciado. Em síntese, tanto a enunciação quanto o conteúdo do enunciado passam a ser descritos por meio de encadeamentos argumentativos (evocados implícita ou explicitamente).

O modo de aparição do conteúdo também é um fator determinante, quando se busca pensar em "argumentações enunciativas". Principalmente o modo do concebido - que se distingue do modo do en- 
contrado e do modo do recebido (CAREL, 2011) revelou-se fundamental no estudo de Carel (2018) sobre o poema Noite de substituição de Marc de Larréguy de Civrieux, por exemplo. Subjacente a esse poema, o modo do concebido revela diferentes formas (tons), com unidades representáveis por encadeamentos comportando um eu digo. Entre essas formas, destacam-se o "tom do dizer imposto" - que é "simples", porque é refletido por um único encadeamento argumentativo - e o " tom da reportagem", que é considerado "complexo", porque é refletido por vários encadeamentos, conforme se poderá verificar em Caeiro (2.1).

Determinar esse comportamento manifestado no discurso - também compreendido como um sentimento mostrado - é, segundo defende Carel (2018), um fato de interpretação. Um enunciado em tom do dizer imposto evoca uma concretização do presente e no eu de X DC DIZER X. Já um enunciado em tom de reportagem evoca uma concretização no presente e no eu de OLHAR DC SABER e de VER DC DIZER. Nesse caso de reportagem, sempre aparece a presença de um eu digo num dos encadeamentos evocados, cuja presença do dizer atual caracteriza o modo do concebido. Eis que a enunciação aparece aí como efetivamente parte do sentido do enunciado, da mesma forma que o conteúdo comunicado. Portanto, segundo essa perspectiva teórica, a enunciação não é um fenômeno analisável por ferramentas exteriores à língua.

\section{A Teoria dos Blocos Semânticos aplicada à interpretação textual}

3.1 O Guardador de Rebanhos: análise do poema II (L.G.)

Constituído por um conjunto de 49 poemas escritos em 1914 pelo heterônimo Alberto Caeiro, de Fernando Pessoa, O Guardador de Rebanhos somente foi publicado em 1925, com exceção do poema VIII publicado em 1931. A biografia de Alberto Caeiro - registrada pelo próprio Pessoa - define-o como um homem simples, sem instrução e profissão, tendo vivido quase toda sua vida no campo. Daí o fato de os elementos campestres presentes na obra construírem um discurso impregnado de panteísmo, em que o eu lírico observa os elementos da natureza, não apenas para falar sobre a vida, mas também para associá-los à divindade que se apresenta em toda singularidade do universo. Segundo palavras do heterônimo Álvaro de Campos, O Guardador de Rebanhos "era como a voz da terra, que é tudo e ninguém".

Assim, ao redefinir poeticamente o que vê, Caeiro rompe paradigmas cristãos do mundo ocidental, cria paradoxos linguísticos, testa os limites da compreensão e abre seu discurso às mais diversas interpretações. Para tanto, o poeta deixa fluir sua própria subjetividade fortemente ligada à pureza, à simplicidade e à ingenuidade. De maneira distinta de um pseudônimo que apenas oculta o nome do autor vale salientar aqui -, o heterônimo tem biografia e apresenta-se efetivamente como uma pessoa de carne e osso no mundo. Os conhecidos heterônimos portugueses tais como Alberto Caeiro, Álvaro de Campos, Ricardo Reis e Bernardo Soares têm, portanto, subjetividade própria; todos são, contudo, criação de um único sujeito real ${ }^{3}$, que é Fernando Pessoa.

A concatenação de um texto ao outro, em 0 Guardador de Rebanhos, não contém pré-requisitos. Ainda que os 49 poemas sejam fruto de uma única noite de insônia de Caeiro, a independência que há entre os textos denuncia um processo criativo inspirado ao acaso. Esse heterônimo é tido como o principal desencadeador do processo poético de Pessoa, cuja "ciência espontânea" criada determina que as sensações geralmente devem antepor-se ao intelecto. A linguagem é aí carregada de tensão: como é possível "pensar-não-pensando" ou, em todo caso, "nãopensar-pensando"? O entrelaçamento de palavras, em Caeiro, ultrapassa as classificações das figuras retóricas e, portanto, apresenta-se aos olhos de um linguista semanticista como um convite à pesquisa.

\footnotetext{
3 A Teoria Polifônica da Enunciação postulada por Ducrot (1984) define o sujeito empírico (SE) como o autor muscular do enunciado e autor intelectual da escolha das palavras e de sua organização gramatical. Por não fazer parte do sentido do enunciado, o SE não constitui interesse do semanticista. Por essa razão, não são evocadas informações sobre Fernando Pessoa neste artigo.
} 
O segundo poema de $O$ Guardador de Rebanhos foi o escolhido para constituir o corpus desta primeira parte da pesquisa divulgada neste artigo, já que - pelo fato de explicitar muito bem as características de Caeiro - revela-se bastante significativo numa investigação cujo objetivo principal é o de mostrar, por meio de um percurso teórico-metodológico de leitura, a interpretação textual sendo guiada pela significação das entidades linguísticas. As noções de encadeamento e aspecto argumentativos são as duas ferramentas escolhidas para nortear a análise apresentada a seguir:

\section{O Guardador de Rebanhos - poema II}

(1) O meu olhar é nítido como um girassol.

(2) Tenho o costume de andar pelas estradas

(3) Olhando para a direita e para a esquerda,

(4) E de vez em quando olhando para trás...

(5) E o que vejo a cada momento

(6) É aquilo que nunca antes eu tinha visto, (7) E eu sei dar por isso muito bem...

(8) Sei ter o pasmo essencial

(9) Que tem uma criança se, ao nascer,

(10) Reparasse que nascera deveras...

(11) Sinto-me nascido a cada momento

(12) Para a eterna novidade do Mundo...

(13) Creio no Mundo como num malmequer,

(14) Porque o vejo. Mas não penso nele

(15) Porque pensar é não compreender...

(16) O Mundo não se fez para pensarmos nele

(17) (Pensar é estar doente dos olhos)

(18) Mas para olharmos para ele e estarmos de acordo...

(19) Eu não tenho filosofia: tenho sentidos...

(20) Se falo na Natureza não é porque saiba o que ela é,

(21) Mas porque a amo, e amo-a por isso,

(22) Porque quem ama nunca sabe o que ama

(23) Nem sabe porque ama, nem o que é amar...

(24) Amar é a eterna inocência,

(25) $E$ a única inocência é não pensar...

(O Guardador de Rebanhos. In Poemas de Alberto Caeiro. Fernando Pessoa. (Nota explicativa e notas de João Gaspar Simões e Luiz de Montalvor.) Lisboa: Ática, 1946 (10 ed. 1993).

De um ponto de vista linguístico, pode-se dizer que o sentido global desse poema demonstra revelar suas raízes numa efetiva relação entre enunciação e argumentação. $\mathrm{O}$ emprego recorrente de ver e olhar ao longo do discurso - marcadores da presença do locutor - são fortes indícios linguísticos da suprema- cia do sentir em relação ao pensar. Assim, o primeiro verso permite evocar, de início, o encadeamento implícito (1):

(1) eu vejo nitidamente tudo, portanto eu digo que meu olhar é como um girassol, entendido como concretizando o aspecto não decalado VER DC DIZER

A comparação presente nesse encadeamento evocado implicitamente do primeiro verso põe em relação duas competências: (1) a capacidade de ver com nitidez do próprio locutor e (2) a particularidade da flor (denominada girassol) de seguir continuamente a luz do sol. Trata-se, aqui, de uma enunciação focalizada no próprio locutor, visto que ele emprega um "eu vejo" para depois se sentir autorizado a "dizer", isto é, a "enunciar" o que vê. Eis que se depreende daí o aspecto não decalado VER DC DIZER contido na significação de "ver".

O grupo dos cinco versos seguintes (de 2 a 6) modifica, em certa medida, a maneira de exprimir a enunciação do locutor e incide sua ênfase sobre o verbo "olhar", conforme se verifica no encadeamento implicitamente evocado (2):

(2) eu ando olhando para a direita, para a esquerda e às vezes para trás, portanto eu vejo o que nunca tinha visto, compreendido como concretizando o aspecto decalado OLHAR DC SENTIR

Embora o tempo gramatical desse trecho do poema seja o presente - assegurando o modo enunciativo do concebido -, o tom aí é essencialmente factual. De acordo com as conclusões de Carel (2018), a partir do estudo do poema Noite de substituição de Marc de Larréguy, os enunciados no modo do concebido e no tom de reportagem, por exemplo, evocam uma concretização no presente e no eu. Assim, a principal diferença entre Fernando Pessoa e Marc de Larréguy é que o tom factual de Pessoa é simples e concretiza o aspecto OLHAR DC SENTIR, inscrito na significação do verbo "olhar". Trata-se, pois, de uma diferença discursiva sendo revelada na e pela própria natureza argumentativa da língua. 
O processo interpretativo dos versos seguintes (de 7 a 12) - manifestos notadamente no mesmo modo do concebido e no mesmo tom factual do trecho anterior - tende a evocar um encadeamento implícito do tipo de (3), conforme se pode conferir:

(3) eu sei manter em mim o encantamento de um recém-nascido, portanto eu me sinto renascido, a cada instante, na serena novidade do mundo, compreendido como concretizando o aspecto decalado GUARDAR O ENCANTAMENTO INFANTIL DC RENOVAR-SE

Essa análise permite verificar que o trecho em foco exige maior esforço interpretativo, sobretudo se for comparado ao trecho anterior. Por isso, torna-se necessário realizar uma decalagem mais expressiva do encadeamento até o aspecto para que a significação linguística aí presente seja efetivamente acessada pelo alocutário. Desse fenômeno linguísticodiscursivo aqui revelado, conclui-se que, quanto mais carregada de singularidade do locutor for a maneira de expressão do conteúdo no discurso, mais reflexiva deverá ser a leitura realizada pelo alocutário. Só assim - por meio da decalagem - a significação das palavras é acessada e a interpretação textual pode ser efetivada com sucesso.

Diferentemente dos dois excertos anteriores (2-6 e 7-12) - cujo sentido global é observado num único encadeamento - a representação do sentido construído no terceiro excerto do poema (dos versos 13 a 19) deve levar em conta as significações de "ver", "pensar", "existir" e "sentir", que são termos caracterizantes fundadores dos encadeamentos (4) a (10):

(4) eu vejo o mundo, portanto eu acredito nele (evocado implicitamente)

(5) eu vejo uma margarida, portanto eu acredito nela (evocado implicitamente) VER DC ACREDITAR (não decalado)

(6) pensar, portanto não compreender o mundo (evocado explicitamente)

PENSAR DC NEG-COMPREENDER (não decalado)
(8) pensar, portanto estar doente dos olhos (evocado explicitamente)

PENSAR DC NEG-VER (decalado)

(7) existir no mundo, portanto não pensar (evocado implicitamente)

(9) existir no mundo, no entanto olhá-lo apenas com concordância (evocado implicitamente) EXISTIR NO MUNDO DC APENAS ESTAR DE ACORDO (não decalado)

(10) eu não tenho filosofia, portanto eu tenho sentidos (evocado implicitamente)

NEG-PENSAR DC SENTIR (não decalado)

Os encadeamentos evocados desse trecho do poema (dos versos 13-19) apresentam comportamentos enunciativos distintos. Por um lado, nota-se que (4), (5) e (10) contêm o eu no presente, a partir do que defendemos a tese segundo a qual eles constituem argumentações enunciativas em tom factual, no modo do concebido. Por outro lado, os encadeamentos de (6) a (9) desenvolvem-se em tom factual, no modo do encontrado; portanto, não constituem argumentações enunciativas. É também o que se passa no trecho que encerra o poema (dos versos 20-24), conforme se pode verificar:

(11) eu falo da Natureza, no entanto eu não sei o que ela é (evocado explicitamente)

FALAR DE X PT DESCONHECER X (não decalado)

(12) eu desconheço a Natureza, portanto eu a amo (evocado explicitamente)

DESCONHECER DC AMAR (não decalado)

(13) amar, portanto nada saber (evocado explicitamente)

(14) amar, portanto ser inocente (evocado explicitamente)

AMAR DC SER INOCENTE (não decalado)

(15) ser inocente, portanto não pensar (evocado explicitamente)

SER INOCENTE DC NEG-PENSAR (não decalado)

Enquanto os encadeamentos (11) e (12) contêm a presença explícita do eu - constituindo argumentações enunciativas no mesmo modo do concebido e no tom factual do restante do poema -, os encadeamentos (13), (14) e (15) estão no modo do 
encontrado em tom factual. Portanto, não constituem argumentações enunciativas.

3.2 Análise de um fragmento do Livro do desassossego por Bernardo Soares (G.C.)

Surge dos lados do oriente a luz loura do luar de ouro. O rastro que faz no rio largo abre serpentes no mar.

O Livro do desassossego por Bernardo Soares é uma obra póstuma e inacabada. Na sua estrutura, o Livro do desassossego é um Zibaldone à maneira daquele de Giacomo Leopardi - uma coletânea de gênero diversificado: pensamentos, aforismos, fragmentos literários. O que hoje está publicado com o título Livro do desassossego, por Bernardo Soares, é um conjunto de textos, mais ou menos curtos, que apesar dos esforços de reconstituição do corpus segue uma ordem bastante aleatória. A sua riqueza é igual somente à sua extrema requinte.

A compreensão dessa passagem, extremamente simples e terrivelmente complexa ao mesmo tempo, apresenta muitos problemas.

A leitura standard é a seguinte:

A leste desponta a luz loura do luar de ouro. 0 rastro que faz no rio largo abre serpentes no mar.

Essa leitura é perfeitamente possível e coerente. Um exegeta que compreendesse desse modo faria uma escolha precisa: a de ser literal.

Em nossa analise, opomos às leituras tradicionais - de natureza referencial - uma leitura guiada pela TBS.

Observamos imediatamente a primeira palavra do fragmento: surge. Surge pode ser duas coisas em português: o verbo surgir no presente do indicativo, terceira pessoa do singular; ou o verbo surgir no imperativo, segunda pessoa do singular. No fragmento de Pessoa, surge tem como sujeito gramatical a luz loura: portanto, trata-se do presente do indicativo.

A luz surge. Mas, nesse caso, qual a função de a luz? Entre as suas acepções principais, surgir significa: a) aparecer; ou despontar, no caso do sol (ex. O Sol surge no horizonte); b) sarar, restabelecer-se (como na expressão surgir de doença; c) (NÁUTICO) aportar, entrar em porto - e (MARINHA) dar fundo, logo amarrar, atracar.

Qual a função de a luz no fragmento de Pessoa? Dado que é a luz [...] do luar, ela poderia despontar, aparecer, levantar. Trata-se da escolha de leitura clássica, a mais difusa. A lua surge significa a lua aparece. No fragmento de Pessoa, não é a lua que surge: é a sua luz; mas a luz participaria, por extensão, nesse movimento.

Neste momento, aceitamos essa leitura e continuamos na compreensão que ela impõe. De onde levanta a luz desse luar? Dos lados do oriente. Em realidade, a lua levanta a leste; a luz do luar também levantaria a leste: para a felicidade dos referencialistas e dos estudiosos de estilística, que veriam, respectivamente, uma descrição do mundo e uma descrição bem detalhada.

Quanto à sua fisionomia, essa luz é loura e o luar é, por sua vez, de ouro. Um estudioso de estilística encontraria na passagem, ao mesmo tempo, o (estilo) descritivo e uma figura de retórica: a adjetivação (loura, de ouro) e a aliteração (da consoante I, e das vogais $u$ e $o$ ).

Sempre seguindo essa leitura, passamos agora à segunda frase do fragmento: $O$ rastro que faz no rio largo abre serpentes no mar. Então, os problemas começam a manifestar-se.

Fazer um rastro significa "deixar um vestígio, um traço". O que deixa esse "vestígio" nesse fragmento? Sempre a luz.

Esse traço é deixado no rio largo. Essas são as palavras empregadas por Pessoa e essa é a ordem em que essas palavras aparecem: no rio largo. O autor poderia, invertendo o substantivo e o adjetivo, escrever no largo rio, mas ele decidiu privilegiar essa forma: no rio largo - chegaremos rapidamente nesse ponto e às suas consequências semânticas.

Por último, passamos à conclusão do fragmento: $O$ rastro que [a luz] faz no rio largo abre serpentes no mar. Uma coisa é certa: se mantivermos uma leitura referencial ou estilística, tudo o que podemos compreender dessa passagem - e tudo o que podemos afirmar a seu propósito - é que temos uma metáfora. 
Entretanto, no máximo, essa leitura pode dar uma resposta a serpentes, mas não ao verbo abrir (abre). No caso do verbo, a metáfora, e a sua maneira figurada de empregar as palavras, também se calam e permanecem mudas: não compreendemos mais o sentido desta escolha lexical - abrir serpentes.

Agora, recomeçamos do início e tentamos sair das leituras referenciais e da estilística. Sobretudo, tentamos fazer ouvir a riqueza do texto e tentamos compreender, ao mesmo tempo, o seu sentido e os seus matizes. Recordamos: o que queremos é poder explicar quer o sentido local das palavras e das expressões - a sua significação, e que esquemas desse valor semântico operam nas diferentes passagens do fragmento -, quer o sentido global do texto.

Começamos pelo sentido do verbo que abre esse fragmento: surgir (surge). Já sublinhamos que esse verbo significa aparecer, levantar; e, na linguagem da marinha, entrar em porto, amarrar. Portanto, substituímos levanta por aporta: a luz aporta.

À primeira vista, essa escolha pode parecer singular. Mas fazemos o esforço de ouvir como fica o resto do texto, se fizermos esse tipo de escolha. Agora temos "a luz aporta" dos lados do oriente. Antes a compreensão era "a leste", porque ficávamos numa visão fundada sobre o recurso à referência. Mas, na verdade, essa leitura referencial acabava, para ficar referencial, por trair a sua própria alma. Certamente, oriente transformava-se na expressão - muito cardeal - "a leste", mas o sentido da expressão dos lados de era um pouco prolongado, porque normalmente esperamos ouvir do lado do oriente, no singular, não dos lados do oriente, no plural.

Colocada no plural, a expressão - dos lados de - não significa mais "a leste". Ao contrário, ela faz ouvir a expressão de todos os lados, que significa "em toda a parte". Por quê? Porque, em português, as expressões que empregam lado se apresentam no singular. É muito raro haver expressões em que a palavra lado se apresente no plural; entre essas expressões, temos de todos os lados e de ambos os lados.

Nesse texto, porém, há muito mais; este plural imprevisto - dos lados - leva o leitor a reconsiderar também (do) oriente. A expressão geográfica do ponto cardeal deveria normalmente se fazer com a palavra lado no singular:

[1] Do lado de oriente.

Então, duas perguntas se abrem: a) por que a palavra lado apresenta-se no plural (lados)? b) como compreender a palavra oriente - essa palavra significa sempre leste?

A relação entre as duas é crucial. Do lado de oriente significaria a leste; mas a presença do plural (dos lados) obriga não só a reconsiderar a expressão dos lados, mas também o sentido da palavra oriente. Uma indicação hermenêutica vem daquilo que lados significa, a saber: flancos, ilhargas.

Há uma expressão que é particularmente útil como elemento hermenêutico:

[2] Os lados da colina.

O que ouvimos graças à expressão dos lados do oriente? Podemos distinguir:

[3] Os flancos de Lisboa.

Mas, como dizíamos, o plural - dos lados não faz ouvir "do lado de" ("do lado do oriente", logo: "a leste"), mas uma outra expressão, a saber: de todos os lados ("por todo o lado, por toda a parte"). Agora podemos acrescentar que, graças à combinação de todos os elementos que enumeramos, o que devemos compreender no texto é:

[4] Sobre todas as colinas de Lisboa.

logo:

[5] Sobre toda a cidade de Lisboa.

Precisemos alguns pontos.

Começamos pela presença da preposição de $(d e+o s=d o s)$ na expressão dos lados. Embora entendamos surge como "aporta" (em lugar de "levanta"), a preposição fica associada ao verbo surgir entendido como levantar, a saber: dos (lados). A preposição associada a surgir entendido como aportar teria sido nos $(e m+o s)$. 
Vemos as duas expressões que são a base da passagem construída por Pessoa. Do ponto de vista lexical, a passagem é particularmente complexa; mas as expressões empregadas são banais, emprestadas da língua ordinária, quotidiana:

[6] A lua surge do lado do oriente.

[7] O barco surge no porto.

Gramaticalmente, as duas expressões estão no singular - do lado do, no porto. A preposição fica aquela do verbo surgir entendido como levantar, mas a sintaxe é só parcialmente aquela dos empregos ordinários. Pessoa mantém a preposição de, mas substitui o seu emprego ordinário no singular ("do lado") por um emprego - imprevisível - no plural ("dos lados").

Precisemos também dois outros pontos. 0 primeiro: como aparece Lisboa no texto? O segundo: o que exprime?

A palavra Lisboa - gramaticalmente, um nome próprio - não está presente no fragmento; todavia, a sua significação intervém na construção do sentido. A significação da palavra Lisboa contém colinas (no plural) e essa palavra, se bem que ausente no texto em foco, está disponível intratextualmente. Estando fisicamente ausente nesse fragmento, Lisboa não pode estar presente na frase ou no período argumentativo como termo constitutivo ${ }^{4}$; não obstante, essa palavra e a sua significação estão disponíveis intratextualmente no Livro do desassossego.

Nesse fragmento, Pessoa evoca Lisboa graças à presença, no texto, da palavra lados. No fragmento, lados lembra colinas e, dessa maneira, Lisboa.

A palavra Lisboa percorre toda a obra de Pessoa, o Livro do desassossego e uma parte da significação de Lisboa - o elemento colinas - passeia pelo fragmento e toma parte na construção do sentido. Portanto, graças a Lisboa podemos ouvir, na palavra lados, colinas.

Um esclarecimento de caráter semânticocomparativo. Em nossa analise, fazemos a hipótese de que a palavra Lisboa contenha o elemento colinas.
Isso é certamente verdadeiro para todos os locutores lusófonos de Portugal: a palavra Lisboa evoca colinas. Os lusófonos do Brasil, ao contrário, poderiam não associar Lisboa e colinas: neste caso, teríamos uma diferença entre o português de Portugal e o português brasileiro.

Passamos à palavra oriente. Oriente seria uma marca referencial? Absolutamente não: oriente é uma marca puramente enunciativa. Oriente indica que há um ponto de vista, diz que há alguém que guarda; alguém que guarda e que diz eu guardo: dizendo oriente, a pessoa que guarda-diz eu guardo.

Mas oriente não é o único elemento enunciativo. Surge também - o verbo que abre o fragmento também é enunciativo. Surge não descreve nada: está lá para fazer ouvir:

[8] Guardo a luz loura do luar de ouro (...).

Naturalmente, guardo não é uma maneira de atribuir a propriedade de guardar a eu; guardo diz que há um eu que está guardando, é uma marca da presença de um locutor.

Um pormenor importante: surge exprime guardar; dos lados de evoca, ao contrário, ver. Dos lados de faz ouvir lá abaixo, obriga o olhar a ir longe, a procurar.

Enfim, a luz loura do luar de ouro introduz o último elemento da enunciação, a saber, o tom em que o locutor fala. O locutor enuncia cantando que:

[9] A luz loura do luar de ouro se difunde sobre toda a cidade de Lisboa.

As aliterações (da consoante l, e das vogais $u$ e o) estão lá para dizer isso, para fazer ouvir que o locutor diz cantando. A repetição de loura e ouro também tem essa função. As palavras loura e ouro seriam redundantes se fossem descritivas, mas a sua função no texto é a de criar o ritmo cantante que é inaugurado pelo tom da enunciação.

Agora, só um elemento falta: o advérbio lentamente:

\footnotetext{
${ }^{4}$ A esse propósito, confira-se o artigo de Carel publicado neste número.
} 
[10] A luz loura do luar de ouro se difunde lentamente sobre toda a cidade de Lisboa.

De onde vem lentamente? Lentamente vem de aportar, porque esse verbo evoca o elemento "lentidão", o feito de "mover lentamente". A significação de aportar contém o esquema:

\section{[11] MOVER LENTAMENTE DC ATINGIR.}

Graças à escolha deste verbo, "aportar", o locutor explica não só que ele percebe a luz do luar como "entrante" na cidade, mas ele também precisa o modo como a luz pousa na cidade de Lisboa: lentamente.

Agora podemos passar à segunda frase do fragmento: $O$ rastro que faz no rio largo abre serpentes no mar. Revelamos, imediatamente e sem reticências, o ponto de partida da nossa reflexão: no fragmento, a expressão que atraiu mais a nossa atenção foi fazer o rastro, "deixar um vestígio, um traço". Foi essa expressão que nos convidou a reconsiderar o sentido do verbo surgir e que, portanto, orientou a nossa compreensão do texto. Por quê? Porque, na expressão fazer o rastro, o que é dito linguisticamente é que o traço é deixado atrás, não projetado à frente.

A luz faz um rastro, porque ela surge, "a luz deixa atrás de si um traço, porque ela entra em porto, dirige-se na direção da cidade":

[12] A luz surge, portanto faz um rastro.

É a expressão fazer o rastro, combinada com o que segue (abre serpentes no mar), que mostra a luz como "entrante na cidade".

Mas essa entrada na cidade tem um caráter particular. Ela evoca não só, como dizíamos anteriormente, a ideia de lentidão, mas também a ideia de abrigo. A ideia de "abrigo" dessa entrada na cidade é evocada graças ao emprego do verbo abrir. No fragmento, se o traço abre serpentes no mar, é porque alguém - qualquer coisa: a luz - entrou.
A abertura na direção do mar - na direção do exterior - é o que permite a entrada no interior da cidade. Abrir faz ouvir como eco reentrar e reentrar exprime o esquema:

\section{[13] REENTRAR DC PÔR-SE AO ABRIGO.}

Esse esquema também - recordemos - vem da significação de aportar. A esse respeito, as significações de abre e de surge participam na construção de uma mesma ideia; essa ideia é a de "abrigo", de "chegada".

Resumamos e precisemos alguns pontos. Entrar vem da significação de surgir, entendido como aportar. Mas entrar torna-se reentrar no momento textual em que a palavra abre aparece. A ideia de "abrigo" expressa por reentrar aparece neste momento. Antes, ainda não estava presente, porque entrar não exprime o elemento "abrigo". Somente reentrar exprime "abrigo"; portanto, é só quando entrar transforma-se em reentrar graças ao emprego do verbo abre que a ideia de "abrigo" se manifesta.

Continuemos. Se a luz - aportando - dirige-se na direção da cidade, ela deixa atrás de si - no rio largo - um traço de espuma que, chegada na desembocadura, propaga-se, cintilante, reluzente: as serpentes.

[14] A luz surge na cidade, portanto o seu rastro abre serpentes no mar.

A expressão no rio largo é enunciativa, porque ela indica que o locutor guarda algo de familiar.

O locutor não descobre que o rio é largo. Ele redescobre que o rio é largo: o locutor reencontra o rio que ele conhece - e o reconhece.

Não só. O locuor vê o rio "largo", porque ele o guarda: o rio é "largo", porque o rio é "visto". O feito de dizer que o rio é "largo" recorda, uma vez mais, que há um locutor que guarda o rio.

A escolha de escrever rio largo, em lugar de largo rio, é significativa. Com largo rio não ouviríamos mais o olhar dirigido sobre o rio. A título de compreensão, façamos um exemplo: façamos o exemplo do epíteto. No caso do epíteto, "O astuto Ulisses", não 
precisamos aguardar Ulisses para descobrir que ele é astuto. Da mesma maneira, no fragmento, não precisaríamos aguardar o rio para saber que ele é largo.

Com rio largo, o locutor diz reconhecer o rio. No texto de Pessoa, o locutor vive o prazer da familiridade. Rio largo é uma marca da proximidade enunciativa que existe entre o locutor e o que ele diz guardar. Rio largo indica uma aproximação; uma aproximação que se faz graças às palavras: uma intimidade.

Ele reconhece o seu rio e, com o rio, a cidade, a sua cidade: Lisboa. Essa aproximação é feita pelas palavras: largo pertence à significação da palavra que é, como a palavra Lisboa, um nome próprio Tejo; e, dessa maneira, Tejo evoca novamente a palavra Lisboa, porque as significações das duas palavras Tejo e Lisboa partilham o traço semântico largo.

Um efeito de eco cria-se também entre essa sensação de familiaridade e o verbo reentrar. Precedentemente, observamos que, graças ao emprego do verbo abre, entrar transforma-se em reentrar. A luz reentrava na cidade, nesta cidade - Lisboa - que, na sua significação, contém o traço semântico luz. O locutor aguarda a luz reentrar e reconhece essa luz: é a luz da sua Lisboa.

Em resumo, a significação de Lisboa apresenta como traços semânticos colinas e rio largo, mas ela contém também luz, loura e ouro. Portanto, podemos afirmar que esse fragmento de Pessoa desenvolve uma boa parte da significação da palavra Lisboa. O fragmento pode ser visto como um longo desenvolvimento da significação de Lisboa - palavra fisicamente ausente do texto, mas disponível graças ao intratexto, às dinâmicas intratextuais.

Passemos à conclusão do fragmento, abre serpentes no mar.

Comecemos pela palavra serpentes. Por um lado, serpentes introduz, no quadro que Pessoa está pintando, um encrespamento, um elemento ondeante (como no adjetivo serpentino) - logo "dançante". Por outro lado, a palavra serpentes evoca "perigo".

Ao mesmo tempo, no fragmento, existe algo que afasta o elemento "perigo", evocado por serpen- tes. Pousa, sobre Lisboa, um silencioso sentimento de abrigo e proteção. Não encontramos nenhum traço desse "perigo" que a palavra serpentes deveria exprimir. O que afastou as serpentes? Por onde passou o "perigo"?

Do ponto de vista lexical, é o verbo abrir que introduz os elementos "abrigo", "acolhimento", "procurar refúgio"? Lexicalmente, a palavra abrir, com as suas ideias de "abrigo" e de "proteção", é mais forte do que a palavra serpentes, com a sua ideia de "perigo", de modo que abrir transforma serpentes em serpentino.

Na passagem, devemos ler o verbo abrir como deixar sair. Então, a frase $O$ rastro que faz no rio largo abre serpentes no mar transforma-se em $O$ rastro que faz no rio largo deixa sair serpentes no mar. Assim, compreendemos por que, gramaticalmente, o verbo abrir é empregado como verbo transitivo: no texto o rastro não abre a, mas abre alguma coisa (serpentes).

Entretanto, o que deixa sair as serpentes no mar, e como? É a luz que, entrando na cidade, deixa sair as serpentes no mar. A luz abriga-se na cidade e, fazendo isso, protege Lisboa, transformando serpentes em serpentino: da significação de serpentes o que é afastado, posto na parte ${ }^{5}$, é o elemento "perigo".

Em síntese, o que a luz faz é, por um lado, abrigar-se na cidade, procurar um refúgio; por outro, também proteger a cidade com a sua chegada. Uma chegada que deixa sair serpentes no mar e que transforma as serpentes num movimento, numa dança.

Serpentes foi uma palavra transformada em serpentino e da significação de serpentino o que empregamos são os elementos "encrespamento", "ondeante" - logo "dançante". No fragmento, abre-se um diálogo entre o que o locutor guarda e o tom em que ele diz o que está guardando. Um eco cria-se entre a palavra cantante do locutor e o universo dançante que ele diz guardar.

Como dissemos, no fragmento, Pessoa multiplica os elementos enunciativos. O locutor do texto diz guardar. Mais precisamente, ele diz guardar um

\footnotetext{
5 A esse propósito, confira-se o outro artigo de Christopulos publicado neste número.
} 
mundo que se move e que, movendo-se, exprime um ritmo: a sua voz se harmoniza com esse ritmo.

Graças à enunciação, o locutor anuncia o seu olhar e convida o leitor a adotar o seu ponto de vista. Ao nível das imagens, é uma longa, complexa e pormenorizada coreografia que o leitor é convidado a guardar. Nos ouvidos, um canto ressoa: é o locutor que assobia uma ária alegre e melancólica ao mesmo tempo...

...A acuidade dolorosa das minhas sensações, ainda das que sejam de alegria; a alegria da acuidade das minhas sensações, ainda que sejam de tristeza.

Todo o fragmento poderia ser interpretado como uma longa concretização do esquema seguinte (que resumiria o sentido global do texto):

\section{[15] O UNIVERSO DANÇA DC EU CANTO.}

Em suma, esse fragmento suscita numerosas questões. Essas questões são, ao mesmo tempo, linguísticas e de estilística. Duas são as mais importantes.

A primeira questão é aquela do "descritivo". No nosso artigo, recusamos a ideia segundo a qual um fragmento como esse teria um caráter sobretudo descritivo. Ponto após ponto, mostramos que todos os elementos que normalmente são definidos como "descritivos" não são, em realidade, descritivos; esses elementos têm outras funções no texto, isto é, funções mais sutis e complexas do que aquelas que os teóricos do "descritivo" Ihes atribuem.

Uma segunda questão ainda fica: aquela das figuras de retórica; e, mais precisamente, aquela da metáfora. No fragmento em questão, há dois elementos que poderiam ser definidos como "metafóras" pelos estudiosos de estilística.

O primeiro elemento é surge. Bem entendido: se entendemos surge como "aparece", "levanta", o problema não existiria mais - semanticamente, a luz surge seria como dizer a luz é. Todavia, caso entendêssemos surge como "aporta", a pergunta seria a seguinte: há metáfora? Sejamos claros sobre esse ponto: todas as teorias da metáfora propostas até hoje implicam a existência de uma dicotomia fundamental: aquela que contrapõe, por um lado, o sentido literal e, por outro, o sentido figurado.

Nós recusamos essa dicotomia. Na nossa opinião, há somente um sentido: o que é produzido pelos elementos da significação das palavras. Naturalmente, há diferentes maneiras de manipular os elementos da significação das palavras: podemos empregar (total ou parcialmente) ou negar (total ou parcialmente) esses elementos; podemos conservar uma parte desses elementos e recusar uma outra e assim por diante. Mas o sentido é um e, quando o sentido vem das palavras, vem da sua significação linguística.

Agora, observamos surge. Em realidade, a luz não faz o que os barcos fazem. Mas essa observação puramente referencial é suficiente para fazer dizer que "A luz aporta" é uma metáfora? Admitamos, neste momento, que "A luz aporta" seja uma metáfora. O que aprendemos se decidimos definir "A luz aporta" como metáfora? A constatação - "sim, é uma metáfora" - obriga-nos a concluir que "A luz aporta" não significa "A luz aporta".

Essa conclusão é exatamente a que não aceitamos. "A luz aporta" significa "A luz aporta" e nada mais. Essa frase significa o que ela significa, a saber: o que essas palavras, organizadas nessa ordem precisa, significam. O sentido desse enunciado, segundo o contexto linguístico-lexical em que está inserido, pode ser parafraseado de muitas maneiras diferentes; mas o que esse enunciado significa não é nada além do que as palavras de que ele está composto significam.

No texto, "aporta" evoca uma parte da sua significação - os esquemas MOVER LENTAMENTE DC ATINGIR e REENTRAR DC PÔR-SE AO BRIGO. No interior da passagem, a luz é vista não só como alguma coisa que se põe ao abrigo na cidade, mas também como alguma coisa que reentra lentamente. O sentido do enunciado, na passagem, é isso, e essa é a sua origem. O sentido vem das palavras, que significam somente o que significam: elas mesmas. "A luz aporta" só significa que "a luz aporta": tudo o que 
interessa, em nível semântico, vem da significação das palavras empregadas. Uma diferença entre um sentido literal e um sentido figurado não existe, pois temos somente um sentido: aquele produzido graças à significação das palavras empregadas. E, mais importante, a significação das palavras é o que é. Nunca dizemos $\mathrm{X}$ para significar $\mathrm{Y}$, como muitas teorias da metáfora afirmam. Quando dizemos $X$ significamos $X$. O sentido vem da significação de $X$, do que é dito: das palavras que escolhemos. Nunca queremos significar outra coisa: queremos significar só o que dizemos: as palavras que empregamos. Sendo $X$ o que dizemos literalmente, tudo vem da significação de $X$.

O mesmo discurso aplica-se à outra passagem do texto que tradicionalmente os estudiosos de estilística definem como "metáfora": O rastro [...] abre serpentes no mar. Já descrevemos precisamente o que cada um dos elementos lexicais desse enunciado faz no nível da construção do sentido. Mais uma vez, tudo o que é produzido, no nível do sentido, vem da significação das palavras e das relações e efeitos que essas significações produzem e entrelaçam juntas. $X$ - O rastro [...] abre serpentes no mar - está dito e $X$ significa somente $X$ : todo o sentido vem dos elementos dos quais $\mathrm{X}$ está formado.

\section{Conclusão}

G. C.

Os estudos apresentados neste artigo partiIham, entre outras coisas, os mesmos instrumentos descritivos e analíticos. A maior parte desses instrumentos é fornecida pela Teoria dos Blocos Semânticos (TBS) elaborada por Marion Carel.

Tais intrumentos propostos pela Teoria dos Blocos Semânticos são particularmente eficazes para a análise dos textos - em especial, dos textos que podem ser extremamente complexos, tanto na sua construção, quanto na sua estrutura: a saber, os textos literários.

Contrariamente às outras teorias descritivas e/ou analíticas - por exemplo a teoria da isotopia, lançada por Greimas e continuada por Rastier -, a TBS não insiste no conceito de "repetição". Segundo a TBS, um texto coeso não é um texto coeso porque alguns traços semânticos se repetem ao longo do texto inteiro. Em vista da sua coesão, podemos perfeitamente reencontrar, em um texto, não os mesmos traços, mas os diferentes traços de uma mesma palavra. Além disso, essa palavra poderia estar ausente do texto: apesar dessa ausência, o texto não se tornaria incompreensível ${ }^{6}$.

$\mathrm{Na}$ perspetiva da TBS, um texto - e principalmente um texto literário - não é uma acumulação de figuras de retórica que imporia ao leitor uma verdadeira decodificação. O texto apresenta - explícita ou implicitamente - palavras. Todas essas palavras combinadas - criam juntas um sentido que vem do seu conteúdo semântico. As palavras de um texto significam: elas não estão no texto para fazer estilo.

Uma das maiores qualidades da Teoria dos Blocos Semânticos é a sua capacidade de unir - em vista de uma compreensão global do texto - o conceito de "decodificação" ao de "interpretação"7 . Tanto no caso da " decodificação", quanto no de "interpretação", um conceito central é aquele de paráfrase argumentativa. Agora, como afirma Carel, todos os enunciados podem ser parafraseados por encadeamentos argumentativos. Portanto, é com uma reflexão sobre esse conceito - tão importante para a TBS que queremos concluir o nosso artigo.

No contexto da Teoria dos Blocos Semânticos, os encadeamentos argumentativos são, com certeza, um elemento fundamental de cada compreensão, tanto em nível de enunciado, quanto em nível de períodos argumentativos sobre os quais um texto se organiza. Mas os encadeamentos argumentativos têm também uma outra função: em nossa opinião, tão importante quanto aquela de permitir ao leitor compreender. Essa função é a de manter intacta a complexidade do texto.

Os encadeamentos argumentativos são essa etapa intelectual em que o leitor, sem querer chegar

\footnotetext{
${ }^{6}$ Para mais informações nesse sentido, recomendamos a leitura de G. Christopulos, (2018) «Au delà de l'isotopie », SHS Web of Conferences, vol 46, article $n^{\circ} 06004,6^{\text {ème }}$ Congrès Mondial de Linguistique Française, https://doi.org/10.1051/shsconf/20184606004.

7 A esse propósito, confira-se o artigo de Carel publicado neste número.
} 
imediatamente à compreensão global do sentido compreensão cuja natureza é sempre doxal -, hesita entre as palavras do texto. Os encadeamentos já se situam em um nível "intelectual", porque já não estamos mais apenas no nível das sensações: em parte, o esforço hermenêutico já foi lançado. No entanto, em lugar de passar às palavras que explicitarão o sentido das palavras do texto, o leitor ainda fica entre as palavras do texto.

A natureza dessa hesitação é a que o leitor partilha com o viajante. O viajante está perpetuamente a ponto de hesitar entre a escolha de ficar - de ficar um pouco mais - e a possibilidade de partir de novo. O leitor vive esse mesmo sentimento. É preciso partir de novo - até se apressar - na direção do fim da nossa viagem hermenêutica?

Que a resposta a essa última pergunta seja "sim" ou "não", tanto o leitor, quanto o viajante sabem que a beleza de uma viagem é a de poder sempre voltar para os lugares deixados. Esse é o sentido da viagem, de todas as viagens. Não aquele de chegar ou de acrescentar uma etapa ou uma escala, mas o de voltar. O sentido profundo do vóotos não é regressar, mas voltar. A intimidade de cada nostalgia não está no regresso: está no retorno.

Esta é a função dos encadeamentos no contexto da Teoria dos Blocos Semânticos: satisfazer a nossa nostalgia, restituir ao exegeta a sua alma de viajante. Somos todos gratos à TBS por nos permitir poder fazer isso.

\section{Referências}

ANSCOMBRE, Jean-Claude; DUCROT, Oswald. L'argumentation dans la langue. Bruxelles : Mardaga, 1983.
CAREL, Marion. L'Entrelacement argumentatif. Lexique, discours et blocs sémantiques. Paris : Éditions Honoré Champion, 2011.

CAREL, Marion. Introduction. In : CAREL, Marion. (Org.). Argumentation et polyphonie: de Saint Augustin à Robbe-Grillet. Paris: L'Harmattan, 2012. p. 7-58.

CAREL, Marion; DUCROT, Oswald. La semántica argumentativa: una introducción a la teoría de los bloques semánticos. Edición: María Marta Negroni e Alfredo M. Lescano. Buenos Aires: Colihue, 2005.

CAREL, Marion. Signification et argumentation. Signo, Santa Cruz do Sul, v. 42, n. 73, jan. 2017. ISSN 1982-2014.

Doi: http://dx.doi.org/10.17058/signo.v42i73.8579.

CAREL, Marion. Les argumentations énonciatives Letrônica, Porto Alegre, v. 11, n. 2, p. 125-143, abril-jun. $2018 . \quad$ Doi: http://dx.doi.org/10.15448/19844301.2018.2.30475

CAREL, Marion. Interprétation et décodage argumentatifs. Signo, Santa Cruz do Sul, à paraître.

CHRISTOPULOS, Giorgio. "Au delà de l'isotopie », SHS Web of Conferences, vol 46, article n06004, 2018, $6^{\text {ème }}$ Congrès Mondial de Linguistique Française, https://doi.org/10.1051/shsconf/20184606004.

CHRISTOPULOS, Giorgio. As palavras são miradouros. Pessoa: uma aguda alegria. Signo, Santa Cruz do Sul, à paraître.

DUCROT, Oswald. Le dire et le dit. Paris : Les Éditions de Minuit, 1984.

DUCROT, Oswald. «TopoAet formes topiques», Bulletin d.tudes de linguistique fransaise, n22, 1988, p.1-14.

DUCROT, Oswald. Dire et ne pas dire: Principes de sémantique linguistique. 3ed. Hermann éditeurs des sciences et des arts. Paris, 1991.

SAUSSURE, Ferdinand de. Écrits de linguistique générale. Texte établi et édité par Simon Bouquet et Rudolf Engler. Éditions Gallimard. Paris, 2002.

\section{COMO CITAR ESSE ARTIGO}

GOMES, Lauro; CHRISTOPULOS, Giorgio. Ler Pessoa. Dois estudos semânticos em torno de sua obra poética. Signo, Santa Cruz do Sul, v. 44, n. 80, ago. 2019. ISSN 1982-2014. Disponível em: <https://online.unisc.br/seer/index.php/signo/article/view/13721>. Acesso em: doi: https://doi.org/10.17058/signo.v44i80.13721 